\title{
Panorama da utilização de sistemas de gestão de custos em hospitais município de Tangará da Serra - MT
}

\author{
Nome \\ Luana Graielle Rodrigues Martins \\ Instituição/Afiliação \\ Universidade do Estado de Mato Grosso - UNEMAT \\ País \\ Brasil \\ Resumo da \\ Biografia \\ Bacharel em Ciências Contábeis \\ Auxiliar de contabilidade do Escritório Minerva Contabilidade \\ Nome \\ Paulo Cesar Souza \\ Instituição/Afiliação \\ Universidade do Estado de Mato Grosso - UNEMAT \\ Secretaria de Estado de Saúde \\ País \\ Brasil \\ Resumo da \\ Biografia \\ Bacharel em Ciências Contábei \\ Doutor em Ciências da Saúde \\ Professor da UNEMAT \\ Contador da SES/MT \\ Contato principal para correspondência.
}

\section{RESUMO}

A gestão de custos é um elemento de grande importância a fim de apoiar o processo decisório. Diante da importância, este trabalho objetivou verificar a situação dos hospitais do município de Tangará da Serra - MT quanto à utilização de sistemas de gestão de custos. O estudo caracteriza-se como descritivo e exploratório, com abordagem quantitativa. Foram pesquisados quatro hospitais, dos quais três são privados com finalidade lucrativa e um público. Todos os gestores entendem a importância da existência de sistema de gestão de custos na organização, embora nenhum deles realizem todo processo, visto que registram e geram apenas informações parciais sobre os custos. Todos os gestores afirmaram que desejam implantar sistema de gestão de custos em suas organizações. Ficou evidente que os hospitais pesquisados ainda estão deficientes quanto à utilização de sistema de custos, mostrando a necessidade de aprimoramento nos instrumentos de produção de informações para a tomada de decisão.

Palavras-chave: Gestão de custos; Contabilidade de custos; Custos hospitalares. 


\section{Revista \\ UNEMAT de \\ Contabilidade}

v. 8, n. 16,2019

\section{INTRODUÇÃO}

As organizações hospitalares são complexas, dada a multiplicidade de categoriais profissionais e serviços prestados em seu interior. Esta complexidade inerente à natureza da organização, torna igualmente complexa a sua gestão, especialmente no aspecto econômicofinanceiro (SCHIESARI, 2013).

Desse modo, a tomada de decisão, a fim de que seja mais assertiva necessita estar embasada em informação. Para tanto, as instituições inseridas no âmbito da assistência à saúde no Brasil, necessitam de modernização gerencial, com a utilização de sistemas de custos que sejam capazes de produzir informações para orientar os gestores, promover o controle ideal das atividades e correta tomada de decisão (MINISTERIO DA SAÚDE, 2006).

$\mathrm{O}$ avanço tecnológico e as fortes mudanças no contexto econômico vêm fazendo com que a contabilidade de custos se torne cada vez mais importante para a melhoria nos processos de gestão das organizações hospitalares (ABBAS, 2001). Assim, a apuração de custos em estabelecimentos hospitalares torna-se uma tarefa abrangente levando em conta a diversidade dos serviços prestados, o que exige inicialmente uma delimitação dos sistemas de custos e um sistema de informação eficiente (BONACIN; ARAÚJO, 2010).

O trabalho de apuração e controle de custos em instituições de saúde como os hospitais, pode produzir diversos benefícios tais como: são utilizados como instrumentos eficazes de gestão e acompanhamento dos serviços; possibilitam a implantação de medidas corretivas visando o melhor desempenho da organização; auxilia na definição ou redefinição das prioridades; propicia o aumento da produtividade e a racionalização do uso de recursos, além de outras possíveis medidas administrativas (MINISTÉRIO DA SAUDE, 2006).

A gestão de custos é um instrumento necessário às instituições hospitalares a fim de melhorar o desempenho da organização e redefinir prioridades na utilização dos recursos disponíveis (MARTINS; PORTULHAK; VOESE, 2015).

Assim, diante da importância da gestão de custos como instrumento de gestão nos hospitais surgiu a pergunta principal desta pesquisa: Os hospitais do município de Tangará da Serra - MT utilizam sistema de gestão de custos e se baseiam nas informações produzidas para a tomada de decisão?

O objetivo geral deste trabalho é verificar se os hospitais utilizam sistema de gestão de custos e se baseiam nas informações geradas para tomada de decisões, tendo os seguintes objetivos específicos: Caracterizar os hospitais quanto ao seu perfil socioeconômico; verificar 
se os hospitais utilizam sistema de gestão de custos; analisar, dentre os que utilizam sistema de gestão de custos, se as informações produzidas são efetivamente aplicadas à tomada de decisão.

As organizações hospitalares evoluíram muito desde seu surgimento e com esse progresso veio também a necessidade de sistemas de gestão mais elaborados para auxiliar os gestores. O grande desafio na gestão dos hospitais privados é acompanhar esse mercado crescente e continuar financeiramente e economicamente estável. Para os hospitais públicos, o grande desafio é racionalizar a aplicação dos recursos escassos existentes no SUS, de modo a maximizar os serviços prestados à população. Nesse cenário, a gestão de custos tem fundamental importância, pois "pode ser aplicada com considerável sucesso nas organizações hospitalares a fim de maximizar a eficiência” (SOUZA; SCATENA, 2010).

Além disso, a situação dos hospitais no Brasil configura uma crise nesse tipo de assistência. Segundo o Ministério da Saúde (MS, 2008), essa crise pode ser visualizada em várias dimensões: financeira, política, organizacional, assistencial, de formação profissional e social. Todas essas dimensões tornam a realidade dos hospitais brasileiros de natureza complexa e desafiadora. Assim, dado o papel social dos hospitais, a utilização de ferramentas que aumentem sua eficiência irá contribuir para a maximização de seu papel junto à sociedade.

Como pesquisa acadêmica, este trabalho contribui com a produção de conhecimento de uma organização bastante desafiadora para a realização de pesquisas, visto que possui em seu bojo muitos serviços e profissionais e uma complexidade organizacional bastante significativa.

\section{REFERENCIAL TEÓRICO}

\subsection{Sistema de gestão de custos em hospitais}

A palavra hospital é de raiz latina (Hospitalis) e vem de hospes - hóspedes, porque antigamente nesses locais eram recebidos peregrinos, pobres e enfermos. Esta seria a origem dos hospitais, local que trata pessoas. Sua origem se deu em época muito anterior à era cristã, embora muitos autores tenham se esforçado para demonstrar o contrário. No entanto, não há dúvida de que o cristianismo impulsionou e desvendou novos horizontes aos serviços de assistência sob as mais variadas formas, inclusive os hospitalares (MINISTÉRIO DA SAUDE, 2006).

Assim, os hospitais existem há muito tempo, mas mesmo assim, continuam em constante crescimento e adaptação. Hipócrates foi o precursor dessas mudanças, pois percebia o sofrimento humano com grande preocupação, passando então a desenvolver a medicina empírica a partir de suas observações. Atualmente, as organizações hospitalares são 


\section{Revista

tecnologicamente equipadas, possuem várias normativas e leis que asseguram que esse ambiente seja realmente seguro podendo assim tratar os enfermos. Com essas modificações também surgiu a necessidade de atualizar seus sistemas de gestão e consequentemente os sistemas de custos (CAPPONI, 2015).

Com o passar do tempo as organizações passaram por grandes mudanças, e com essas mudanças os clientes/consumidores começaram a esperar produtos de alta qualidade, maior funcionalidade e com o preço baixo. Essas mudanças são consequências do avanço tecnológico e científico que exigem que empresas do mesmo ramo adotem melhores estratégias ou do contrário perdem espaço no mercado (BRIMSON, 1994).

Sabe-se que para uma empresa alcançar seus objetivos é necessário que haja a produção e análise de informações que permitam formar uma boa estratégia. Desse modo, a empresa poderá elaborar uma estratégia baseada em fatos, com informações seguras, facilitando o alcance de seus objetivos. Uma boa estratégia permitirá que as informações captadas ajudem na adequada formulação de preços, investimento em propagandas, valorizando seu produto e satisfazendo cada vez melhor seus clientes (CASTRO et al., 2015).

Mesmo diante da importância do sistema de apuração e gestão de custos, grande parte das organizações hospitalares não utilizam sistema de custos que seja capaz de fornecer informações úteis para a tomada de decisão ou o fazem de forma precária (ABBAS, 2001).

No âmbito do Sistema Único de Saúde (SUS), por exemplo, os serviços hospitalares são pagos num valor fixo por procedimento, independentemente da quantidade de dias ou dos custos do atendimento. É possível que seja essa uma das razões das dificuldades financeiras de muitos hospitais. Com a utilização de sistemas de custeio e consequente apuração dos custos, estes poderiam ser apresentados ao SUS a fim de cobrar a remuneração do procedimento, de acordo com os serviços prestados. Desse modo, a utilização de sistemas de apuração e gestão de custos torna possível conhecer o custo de cada serviço (MELO, 2004).

A competitividade exige que as organizações se utilizem de todos os meios necessários para se destacar em relação aos concorrentes. A contabilidade auxilia as organizações em seu planejamento e desenvolvimento de estratégias, pois permite que a empresa reduza seus custos e consequentemente possa competir com toda a sua cadeia de valor (CASTRO et al., 2015). 


\title{
2.2 Contabilidade de custos e gestão de custos
}

A contabilidade pode ser utilizada com finalidades distintas dependendo do tipo de usuário a que se destina a informação. Assim, a fim de atender os usuários internos e externos, a contabilidade pode ser classificada em contabilidade financeira ou contabilidade gerencial.

A contabilidade gerencial é realizada com a finalidade de fornecer informações para os administradores, ou seja, aqueles que estão dentro da organização, sendo os responsáveis pela direção e controle das operações. Já a contabilidade financeira está relacionada com o fornecimento de informações para os acionistas, credores e outros usuários externos (PADOVEZE, 2010).

Ao comentar sobre a diferença entre as duas Bruni e Famá (2004) afirmam que a contabilidade financeira ou geral se preocupa com as leis e normas, sendo obrigatória para as entidades legalmente estabelecidas. Seu maior objetivo está ligado ao passado, tendo seus atos e práticas estabelecidos por meio de normas, as quais, muitas vezes, comprometem a utilização da informação para a tomada de decisões. Assim, enquanto a contabilidade financeira dedicase à realização dos registros do patrimônio, obedecendo as normas, convenções e princípios contábeis, a contabilidade gerencial preocupa-se com o processo decisorial e de tomada de decisões.

Por isso, na visão de Crepaldi e Crepaldi (2014) a contabilidade gerencial é assim definida:

\begin{abstract}
Contabilidade Gerencial é o ramo da Contabilidade que tem por objetivo fornecer instrumentos aos administradores de empresas que os auxiliem em suas funções gerenciais. É voltada para a melhor utilização dos recursos econômicos da empresa, através de um adequado controle dos insumos efetuado por um sistema de informação gerencial.
\end{abstract}

Desse modo, a contabilidade de custos pode atender tanto aos objetivos da contabilidade financeira quanto aos objetivos da contabilidade gerencial, dependendo do usuário a que se destina a informação.

De acordo com Martins (2003, p.13) “até a Revolução Industrial (século XVIII), quase só existia a Contabilidade Financeira (ou Geral) desenvolvida na Era Mercantilista, estava bem estruturada para servir as empresas comerciais".

No entanto, a contabilidade evoluiu e passou a ser aplicada a diversas outras áreas. A contabilidade é uma ciência que pode ser estudada de forma ampla ou particular, podendo ser aplicada em vários setores e ramos de atuação. Pode-se encontrar atividades contábeis em 


\section{Revista

setores diversos como: Comercial, bancária, financeira, fiscal, hospitalar e gerencial, sendo essa última aplicada a todos os ramos de atividade (SOUZA, 2010).

A aplicação da contabilidade de custos é muito vasta. Ela tem a capacidade de produzir bons resultados, seja nas empresas estritamente comerciais ou que prestam serviços, como por exemplo, hospitais, lojas, serviços de utilidade pública, institutos educacionais, repartições públicas, etc., tendo sempre em conta, é claro, as peculiaridades de cada tipo de organização (ABBAS, 2001). A gestão de custos aplica os princípios da contabilidade geral para registrar os custos de operação de uma atividade, de tal maneira que seja possível transformar os dados de produção e das vendas em informação útil para tomada de decisão (CALLADO et al., 2008).

Desse modo, a gestão de custos é a utilização da contabilidade de custos como instrumento de apoio à gestão. Para Martins (2003), a contabilidade de custos pode ser um importante instrumento de apoio às decisões gerenciais, tendo em conta que a mesma evoluiu ao longo dos anos, passando a exercer duas novas e importantes funções: auxílio ao controle e ajuda às tomadas de decisão.

Nos últimos tempos, em virtude da globalização da economia, a liderança em custos passou a representar um diferencial entre as empresas, devendo fazer parte de sua estratégia. A fim de que isso seja efetivo, os velhos conceitos da contabilidade de custos necessitam ser substituídos por novos conceitos. A busca do menor custo com a manutenção de bons níveis de qualidade se constitui hoje na melhor estratégia capaz de conduzir as empresas ao sucesso (ABBAS, 2001).

Ao discorrer a respeito da contabilidade de custos, existem alguns conceitos fundamentais que necessitam ser lembrados, os quais serão destacados a seguir.

O primeiro é o conceito de custo. Para Martins (2003, p. 17), "custo é o gasto relativo a bem ou serviço utilizado na produção de outros bens ou serviços". Na visão de Melo (2004, p.21), os "custos são todos os gastos incorridos para a produção de certo bem ou serviço". O autor destaca a importância de se diferenciar os custos das despesas, visto que os dois termos geram confusão, muitas vezes. A grande diferença é que enquanto os custos se destinam a formar o produto, as despesas são todos os gastos ou sacrifícios financeiros com o objetivo de gerar as receitas.

Martins (2003) explica que os custos podem ser divididos em diretos e indiretos, fixos e variáveis, de acordo com sua variabilidade e facilidade de alocação. Quanto à variabilidade, custos variáveis são todos aqueles que se alteram em proporção direta com a quantidade 


\section{Revista

produzida. Num hospital é possível citar como exemplo, o número de exames realizados no serviço de radiologia, medicamentos, materiais hospitalares, gêneros alimentícios, entre outros. Os custos fixos, por outro lado, permanecem inalterados, mesmo havendo variação na quantidade produzida. Pode-se citar como exemplo, a depreciação, o imposto predial, dentre outros (ABBAS, 2001).

Assim, os custos fixos "são custos que em determinado período de tempo e em certa capacidade instalada, não variam, qualquer que seja o volume de atividade da empresa”, já os custos variáveis, "seu valor total altera-se diretamente em função das atividades da empresa. Quanto maior a produção, maiores serão os custos variáveis" (BEULKE; BERTÓ, 2008, p. 21). Ou seja, os custos fixos permanecem iguais independentes do volume da produção já os custos variáveis se alteram.

Existem ainda os custos diretos e indiretos. Os custos diretos "são aqueles diretamente incluídos nos cálculos dos produtos", ou seja, os custos diretos são todos aqueles ligados diretamente ao produto. Como exemplo pode-se citar: matéria prima, mão de obra direta, etc. Já os indiretos são aqueles que "necessitam de aproximações, isto é, algum critério de rateio para serem atribuídos aos produtos" (BRUNI; FAMÁ, 2004, p. 31).

\subsection{Contabilidade de custos e sistemas de custeio}

Não se pode confundir custos com gastos, desembolso ou despesa, o que muito ocorre nas organizações. Gasto é o compromisso assumido diante da aquisição de um produto ou serviço, já desembolso ocorre no momento do pagamento, o que difere de gastos que é apenas um compromisso de pagamento (MARTINS, 2003).

Souza (2010, p. 52) diz que "quando as empresas produziam um único produto ou serviço em sua base produtiva, isso era muito mais simples, afinal, todos os custos fixos e variáveis eram apropriados diretamente a esse único produto ou serviço produzido”. A partir do momento que as empresas aumentaram a diversidade de seus produtos, aumentou-se também a complexidade em se apropriar os custos a cada produto.

Diante disso, surgiram os métodos de custeio. Segundo Souza (2010, p. 52), “os principais métodos de custeio são: teoria das restrições, custeio por absorção, custeio $\mathrm{ABC}$, custeio RKW, custeio direto ou variável”.

Souza (2010) explica que a teoria das restrições é um dos métodos de analise de custos que leva em consideração de cálculo, somente os custos e despesas variáveis, ou seja, materiais diretos e despesas variáveis. 
A Teoria das Restrições foi desenvolvida por Eliyahu M. Goldratt, originalmente com a denominação de Tecnologia da Produção Otimizada (Optimized Production Technology OPT). Esse tipo de custeio estava mais voltado para a administração da produção que orienta a empresa no planejamento e controle. A ideia principal da Teoria das Restrições consiste em verificar as restrições que limitam o ganho da empresa e garantir mais eficiência no gerenciamento destas restrições, bem como, maximizar o lucro diante das condições atuais da empresa (BORNIA, 1994).

O custeio por absorção se caracteriza por apropriar todos os custos do período sejam eles fixos ou variáveis. O método RKW divide a organização por centro de custos onde os custos são distribuídos através de bases (CAPPONI, 2015).

$\mathrm{O}$ custeio $\mathrm{ABC}$ é mais complexo e mais preciso, pois ele faz o rateio baseados nas atividades:

O ABC é um sistema de custos que tem o objetivo de avaliar com precisão as atividades desenvolvidas em uma empresa (tanto industrial, quanto de serviços), utilizando direcionadores para alocar as despesas indiretas de uma forma mais realista aos produtos e serviços. O ABC parte do princípio de que não é o produto ou serviço que consome recursos, mas sim, os recursos são consumidos pelas atividades e estas, por sua vez, são consumidas pelo produto ou serviço (ABBAS, 2001, p. 54).

O custeio direto ou variável, segundo Souza (2010, p. 55), surgiu “com o objetivo de tornar as informações produzidas pelo sistema de custos mais úteis para a tomada de decisões e diminuir essas distorções". De qualquer forma cabe a empresa decidir de acordo com suas necessidades o melhor método de custeio.

\section{METODOLOGIA}

Essa pesquisa se classifica como descritiva e exploratória. Um estudo descritivo expõe claras características sobre o objeto de estudo, envolvendo técnicas padronizadas e bem estruturadas de coleta de dados. Já a pesquisa exploratória consiste num estudo realizado em áreas de pouco conhecimento sistematizado (OLIVEIRA, 2011). Em virtude de haver estudado quatro hospitais, aplicou-se também a estratégia do estudo de casos múltiplos. Estudos de casos múltiplos são aqueles que proporcionam a busca de evidencias em diferentes contextos para que seja possível compreender a realidade dos mesmos (GIL, 2002). Os dados foram trabalhados com uma abordagem qualitativa ao analisar a situação dos hospitais.

A pesquisa foi realizada no município de Tangará da Serra - MT. O município está localizado a 251,6 quilômetros de Cuiabá e conta atualmente com muitos serviços de saúde, dentre estes quatro hospitais. Os hospitais analisados nesta pesquisa foram, um hospital público 
mantido pelo município e três hospitais privados. Os quatro hospitais totalizam 212 leitos de internação (CNES, 2017).

Para a coleta dos dados, foi utilizado questionário contendo 34 perguntas fechadas, o qual foi elaborado com base na dissertação de mestrado de Abbas (2001) e na publicação do Ministério da Saúde, referente à pesquisa realizada para o Programa Nacional de Gestão de Custos (MINISTERIO DA SAÚDE, 2006) e perguntas abertas feitas através de entrevistas aos administradores dos hospitais. O questionário foi respondido pelos administradores dos quatro hospitais pesquisados durante o mês de maio de 2018. Para não expor o nome dos pesquisados foi utilizado os termos A, B, C e D para nomeá-los.

Os dados foram tabulados utilizando o software Excel da Microsoft e apresentados em forma de tabelas. A análise foi realizada por meio da utilização de estatística descritiva e os resultados comparados com outros estudos assemelhados.

\section{RESULTADOS E DISCUSSÕES}

Os resultados da pesquisa serão apresentados de acordo com a estrutura e o agrupamento das questões estabelecidas no questionário. Assim para cada grupo de perguntas do questionário será utilizado um subitem.

\subsection{Perfil socioeconômico}

A Tabela 1 apresenta os dados levantados que possibilitarão analisar o perfil socioeconômico dos hospitais pesquisados.

Quanto ao tempo de existência, é possível verificar que todos os hospitais entraram no mercado entre os anos de 2000 e 2003, datas relativamente próximas. Dentre os quatro três deles atendem as quatro clínicas básicas, ou seja, médica, cirúrgica, obstétrica e pediátrica e o hospital público somente as clínicas médica e pediátrica.

Tabela 1 - Perfil Socioeconômico dos hospitais, Tangará da Serra, 2018.

\begin{tabular}{l|cccc}
\hline Questões aplicadas & Hospital A & Hospital B & Hospital C & Hospital D \\
\hline $\begin{array}{l}\text { 1- Data de início das } \\
\text { atividades. }\end{array}$ & $19 / 08 / 2003$ & $16 / 10 / 2002$ & $27 / 06 / 2000$ & $12 / 09 / 2003$ \\
\hline $\begin{array}{l}\text { 2- Setor a que } \\
\text { pertence. }\end{array}$ & Privado. & Privado. & Privado. & Público. \\
\hline $\begin{array}{l}\text { 3- Tipo da unidade } \\
\text { hospitalar. }\end{array}$ & $\begin{array}{c}\text { Hospital Geral (clínica } \\
\text { médica, clínica } \\
\text { cirúrgica, obstétrica e } \\
\text { pediátrica). }\end{array}$ & $\begin{array}{c}\text { Hospital Geral (clínica } \\
\text { médica, clínica } \\
\text { cirúrgácal obstétrica e } \\
\text { pediátrica). }\end{array}$ & $\begin{array}{c}\text { Hospital Geral (clínica } \\
\text { médica, clínica } \\
\text { cirúrgica, obstétrica e } \\
\text { pediátrica). }\end{array}$ & $\begin{array}{c}\text { Clínica médica } \\
\text { e pediatria. }\end{array}$ \\
$\begin{array}{l}\text { 4- A instituição possui } \\
\text { estrutura formal } \\
\text { definida(Organograma }\end{array}$ & Sim. & Sim. & Sim. & Sim. \\
Funcional)?
\end{tabular}




\begin{tabular}{|c|c|c|c|c|}
\hline $\begin{array}{l}5 \text { - Quantidade de } \\
\text { Funcionários. }\end{array}$ & \begin{tabular}{|c|}
44 médicos, 11 \\
enfermeiros, 53 \\
técnicos de \\
enfermagem, 49 apoio \\
administrativo. \\
\end{tabular} & Não respondeu. & Não respondeu. & $\begin{array}{c}12 \text { médicos, } 4 \\
\text { enfermeiros, } 6 \\
\text { setor } \\
\text { administrativo, } \\
10 \text { outros. } \\
\end{array}$ \\
\hline $\begin{array}{l}6-\quad \text { Ordenamento } \\
\text { Jurídico - Quanto ao } \\
\text { Objetivo }\end{array}$ & Com fins lucrativos. & Com fins lucrativos. & Com fins lucrativos. & $\begin{array}{l}\text { Sem fins } \\
\text { lucrativos. }\end{array}$ \\
\hline $\begin{array}{l}\text { 7- Quantidade de } \\
\text { leitos existentes. }\end{array}$ & De 51 a 150 leitos. & Até 50 leitos. & De 51 a 150 leitos. & Até 50 leitos. \\
\hline $\begin{array}{l}\text { 8- Qual a formação do } \\
\text { diretor administrativo } \\
\text { da organização? }\end{array}$ & Administrador. & Administrador. & Administrador. & Administrador. \\
\hline $\begin{array}{lrr}\text { 9- Quais as fontes de } \\
\text { recursos para } & \text { a } \\
\text { manutenção } & \text { do } \\
\text { hospital? } & & \\
\end{array}$ & $\begin{array}{c}\text { Apenas remuneração } \\
\text { pelos serviços } \\
\text { prestados. }\end{array}$ & $\begin{array}{c}\text { Apenas remuneração } \\
\text { pelos serviços } \\
\text { prestados. }\end{array}$ & $\begin{array}{c}\text { Apenas remuneração } \\
\text { pelos serviços } \\
\text { prestados. }\end{array}$ & $\begin{array}{l}\text { Recursos } \\
\text { públicos } \\
\text { municipais }\end{array}$ \\
\hline
\end{tabular}

Fonte: Dados da pesquisa (2018)

Todos os hospitais pesquisados têm estrutura formal definida. Dos quatro pesquisados três tem finalidade lucrativa (privado) e um é sem fins lucrativos por pertencer ao setor público. Quanto ao porte, dois hospitais têm capacidade menor ou igual a 50 leitos, sendo classificado como pequeno porte e outros dois tem capacidade de 51 a 150 leitos, sendo classificado assim como médio porte (MINISTÉRIO DA SAÚDE, 2004).

Quanto ao número de funcionários, apenas dois dos hospitais dispunham dos dados para fornecer, de modo que ficou prejudicada a comparação. Todos os administradores dos hospitais possuem formação superior em administração, os quais tiveram contato no currículo do curso com conteúdo relacionado às áreas financeiras e de custos, sendo recomendável que os mesmos conheçam com profundidade e utilizem tais conhecimentos. Dentre os quatro, três deles (privados) mantém o hospital com recursos oriundos da receita dos serviços prestados e um (público) com recursos oriundos do município de Tangará da Serra.

\subsection{Sistema de Informação}

A Tabela 2, apresenta os dados relacionadas à utilização de sistemas de informação baseado na tecnologia da informação por parte dos hospitais pesquisados.

Tabela 2 - Utilização de Sistema de Informação baseado em T. I., Tangará da Serra, 2018.

\begin{tabular}{l|cccc}
\hline Questões aplicadas & Hospital A & Hospital B & Hospital C & Hospital D \\
\hline $\begin{array}{l}\text { 1 - Existe área específica T.I. } \\
\text { (tecnologia da informação) } \\
\text { dentro da instituição? }\end{array}$ & Não. & Não. & Não. & Não. \\
\hline $\begin{array}{l}\text { 2-Se a resposta ao item anterior } \\
\text { for "Sim", qual(is) o(s) } \\
\text { serviço(s) realizado(s)? }\end{array}$ & Não respondeu. & Não respondeu. & Não respondeu. & Não respondeu. \\
\hline $\begin{array}{l}\text { 3- Se sua resposta ao item 1 for } \\
\text { "Não" quem realiza a a }\end{array}$ & $\begin{array}{c}\text { Serviço } \\
\text { terceirizado. }\end{array}$ & $\begin{array}{c}\text { Serviço } \\
\text { terceirizado }\end{array}$ & $\begin{array}{c}\text { Serviço } \\
\text { terceirizado }\end{array}$ & $\begin{array}{c}\text { Serviço } \\
\text { terceirizado }\end{array}$ \\
\hline
\end{tabular}




\begin{tabular}{|c|c|c|c|c|}
\hline $\begin{array}{l}\text { manutenção das informações } \\
\text { tecnológicas do hospital? }\end{array}$ & & & & \\
\hline $\begin{array}{l}4 \text { - A instituição possui acesso à } \\
\text { internet? }\end{array}$ & Sim. & Sim. & Sim. & Sim. \\
\hline $\begin{array}{l}5 \text { - Como é realizado o registro } \\
\text { das informações necessárias à } \\
\text { gestão de custos? }\end{array}$ & $\begin{array}{c}100 \% \text { no } \\
\text { computador. }\end{array}$ & $\begin{array}{c}100 \% \text { no } \\
\text { computador. }\end{array}$ & $\begin{array}{c}100 \% \text { no } \\
\text { computador. }\end{array}$ & $\begin{array}{c}100 \% \text { no } \\
\text { computador. }\end{array}$ \\
\hline $\begin{array}{l}6 \text { - Quais das informações a } \\
\text { seguir encontra(m)-se } \\
\text { informatizado(s) e integrado(s) } \\
\text { com outro(s) } \\
\text { serviço(s)/sistema(s): }\end{array}$ & $\begin{array}{l}\text { A.C, A.E, C.D.M, } \\
\text { C.L.C.H, G.M, } \\
\text { G.C,P, R.E.P e L. }\end{array}$ & $\begin{array}{l}\text { A.C, A.E, } \\
\text { C.D.M, C.L.C.H, } \\
\text { G.R.H, G.C, } \\
\text { R.E.P. }\end{array}$ & Não respondeu. & $\begin{array}{l}\text { A.C., A.E, C.D.M, } \\
\text { C.L.C.H, G.R, } \\
\text { G.M, G.R.H, G.C, } \\
\text { P. e L. }\end{array}$ \\
\hline $\begin{array}{l}7 \text { - A instituição possui um } \\
\text { sistema de informação definido } \\
\text { com indicadores } \\
\text { médico/hospitalares } \\
\text { administrativos/financeiros } \\
\text { acompanhados regularmente } \\
\text { pelos seus supervisores, gerentes } \\
\text { e/ou direção? }\end{array}$ & Sim. & Sim. & Sim. & Sim. \\
\hline $\begin{array}{l}\text { 8- Os arquivos e dados da } \\
\text { organização são salvos em } \\
\text { algum servidor externo? }\end{array}$ & Sim. & Não. & Sim. & Sim. \\
\hline
\end{tabular}

Fonte: Dados da pesquisa (2018), Legenda: A.C. (Agendamento de consultas); A.E. (Agendamento de exames); C.D.M. (Controle de dispensação de medicamentos); C.L.C.H (Controle de leitos e censo hospitalar); G.R. (Gerencia de risco); G.M. (Gerenciamento de medicamentos); G.R.H. (Gerenciamento de recursos humanos); G.C. (Gestão de custos); P. (Prontuários); R.E.P. (relatórios estatísticos de produção) e L. (Laboratórios).

Dos hospitais pesquisados nenhum possui área específica de informática, também chamada de Tecnologia da Informação (T.I.) em sua estrutura interna, sendo esse serviço prestado por empresa terceirizada. Todos possuem acesso à internet e o registro das informações necessárias para custos são feitas $100 \%$ no computador. Todos possuem sistema de informação definido com indicadores médicos, administrativos podendo ser acompanhado pelos supervisores, gerentes e direção. Três dos pesquisados possuem arquivos e dados da organização salvos em algum servidor externo.

O motivo de se questionar os hospitais quanto ao sistema de informação baseado na Tecnologia da Informação é que ele é fundamental para a existência de um sistema de gestão de custos. É preciso considerar que "a gestão de custos numa organização hospitalar é um trabalho árduo, o qual só é possível diante da existência um sistema de informação que auxilie no processo de apuração dos custos hospitalares" (SOUZA; SCATENA; MEDEIROS, 2009, p. 121).

Vale lembrar que um bom sistema de informática além de auxiliar na agilidade dos processos das organizações, também auxilia os gestores no controle e análise das informações 
de sua empresa, o que não é diferente com os hospitais. "No Brasil, nas últimas décadas, vem se ampliando o interesse em utilizar bancos de dados originados, de forma rotineira, pelos serviços de saúde, como ferramenta na elaboração de políticas de saúde e no planejamento e gestão de serviços de saúde" (BITTENCOURT; CAMACHO; LEAL, 2006, p. 19).

Segundo Bonacim e Araújo (2010) a apuração de custos em estabelecimentos hospitalares é uma tarefa abrangente, visto que há nesse tipo de organização uma diversidade de serviços prestados, exigindo como primeiro requisito a delimitação dos sistemas de custos e um sistema de informações eficiente.

\subsection{Sistema de gestão de custos}

A Tabela 3 apresenta os dados relacionados à utilização de sistemas de custos. As perguntas foram estruturadas de modo a permitir verificar se os hospitais possuem sistemas de gestão de custos e como o mesmo está estruturado, seja o sistema completo de forma integrada ou mesmo parte do processo.

Os dados mostram que dentre os quatro hospitais pesquisados nenhum utiliza sistema de gestão de custos capaz de apurar o custo dos atendimentos, gerando apenas informações parciais sobres os custos. Assim, percebe-se que a gestão de custos não é um aspecto considerado, na prática, de grande importância para os administradores dos hospitais.

Embora não possuam, os mesmos reconhecem sua aplicação pode trazer benefícios para o hospital, de modo que todos desejam implantar e todos os hospitais dizem ter autonomia para realizar a implantação.

Mesmo não possuindo sistema integrado de gestão de custos, todos os administradores dos hospitais dizem ter um controle interno do consumo de materiais, medicamentos, gênero alimentício, outros itens de consumo, custo com pessoal, serviços diversos, custos indiretos e despesas administrativas. Sendo que três dos hospitais disseram que quem centraliza estas informações parciais de custos é o diretor/presidência e um disse que é o financeiro. Três dos hospitais responderam que realizam gestão de estoque, sendo que dois responderam que fazem a conferência mensal, outro semestral e outro anual.

Tabela 3 - Utilização de sistema de gestão de custos, Tangará da Serra, 2018.

\begin{tabular}{|c|c|c|c|c|}
\hline Questões aplicadas & Hospital A & Hospital B & Hospital C & Hospital D \\
\hline $\begin{array}{l}\text { 1 - A instituição } \\
\text { possui ou está implantando } \\
\text { sistema(s) de gestão de } \\
\text { custo(s) dentro da } \\
\text { organização? }\end{array}$ & Não possui. & Não possui. & Não possui. & Não possui. \\
\hline
\end{tabular}




\begin{tabular}{|c|c|c|c|c|}
\hline $\begin{array}{l}2 \text { - Caso possua sistema(s) } \\
\text { de gestão de custos quem é } \\
\text { o responsável por gerenciar } \\
\text { as informações } \\
\text { relacionadas a custo? }\end{array}$ & Não respondeu. & Não respondeu. & Não respondeu. & Não respondeu. \\
\hline $\begin{array}{l}3 \text { - Caso o hospital possua } \\
\text { ou esteja implantando } \\
\text { sistema(s) de gestão de } \\
\text { custos, qual a metodologia } \\
\text { utilizada? }\end{array}$ & Não respondeu. & Não respondeu. & Não respondeu. & Não respondeu. \\
\hline $\begin{array}{l}4 \text { - Se a resposta ao item } \\
\text { número } 1 \text { for "Não possui", } \\
\text { a instituição deseja } \\
\text { implantar algum sistema de } \\
\text { gestão de custos? }\end{array}$ & Sim. & Sim. & Sim. & Sim. \\
\hline $\begin{array}{l}5 \text { - Se a resposta ao item } \\
\text { anterior for "Sim", a } \\
\text { direção da instituição } \\
\text { possui autonomia para } \\
\text { implantar o sistema de } \\
\text { gestão de custos? }\end{array}$ & Sim. & Sim. & Sim. & Sim. \\
\hline $\begin{array}{l}\text { 6- Mesmo não possuindo } \\
\text { sistema integrado de gestão } \\
\text { de custos, quais } \\
\text { informações r parciais } \\
\text { relacionadas a custos são } \\
\text { geradas? }\end{array}$ & $\begin{array}{l}\text { C.M., C.M.D., C.G.A., } \\
\text { O.I.C., C.P., C.S.D., } \\
\text { O.C.I., D.A. }\end{array}$ & $\begin{array}{l}\text { C.M., C.M.D., C.G.A., } \\
\text { O.I.C., C.P., C.S.D., } \\
\text { O.C.I., D.A. }\end{array}$ & $\begin{array}{l}\text { C.M., C.M.D., C.G.A., } \\
\text { O.I.C., C.P., C.S.D., } \\
\text { O.C.I., D.A.. }\end{array}$ & $\begin{array}{l}\text { C.M., C.M.D., } \\
\text { C.G.A., O.I.C., } \\
\text { C.P., C.S.D., } \\
\text { O.C.I., D.A. }\end{array}$ \\
\hline $\begin{array}{l}\text { 7- Qual o setor responsável } \\
\text { por centralizar e consolidar } \\
\text { as informações do item } 6 ?\end{array}$ & $\begin{array}{l}\text { Diretoria/ } \\
\text { Presidência. }\end{array}$ & $\begin{array}{l}\text { Diretoria/ } \\
\text { Presidência. }\end{array}$ & Financeiro. & $\begin{array}{l}\text { Diretoria/ } \\
\text { Presidência. }\end{array}$ \\
\hline $\begin{array}{lr}\text { 8- } \operatorname{Existe}(\mathrm{m}) & \text { centro(s) de } \\
\text { custos } & \text { identificado(s) } \\
\text { /definido(s) } & \text { para } \\
\text { apropriação } & \text { de receitas e } \\
\text { despesas } & \text { (DRE) por } \\
\text { unidade? } & \end{array}$ & Sim. & Sim. & Sim. & Sim. \\
\hline $\begin{array}{l}\text { 9- Com qual periodicidade } \\
\text { o hospital realiza } \\
\text { conferência do estoque de } \\
\text { material médico? }\end{array}$ & Mensal. & Semestral. & Anual. & Mensal. \\
\hline $\begin{array}{l}\text { 10- A instituição realiza } \\
\text { gestão de estoque? }\end{array}$ & Sim. & Não. & Sim. & Sim. \\
\hline
\end{tabular}

Fonte: Dados da pesquisa (2018). Legenda: C.M. (Consumo de materiais); C.M.D. (Consumo de medicamentos); C.G.A. (consumo de gênero alimentício); O.I.C. (Outros itens de consumo); C.P. (Custo de pessoal); C.S.D. (custos com serviços diversos); O.C.I. (outros custos indiretos) e D.A. (despesas administrativas).

\subsection{Utilização das informações na tomada de decisão}

A Tabela 4 traz os dados que permitirão verificar se os gestores dos hospitais utilizam as informações produzidas pelo sistema de gestão de custos no processo de tomada de decisão.

Tabela 4 - Utilização das informações para tomada de decisão, Tangará da Serra, 2018.

\begin{tabular}{l|llll}
\hline Questões aplicadas & Hospital A & Hospital B & Hospital C & Hospital D \\
\hline
\end{tabular}


1- As informações apuradas pelo sistema de apropriação de custos são discutidas de forma regular com as lideranças (supervisões, gerências ou direção) da instituição para tomada de decisão?

2- Os preços dos serviços são estabelecidos a partir dos custos hospitalares levantados para cada modalidade?

3- O hospital possui um sistema orçamentário formal?

4-São analisadas as diferenças entre os resultados reais e os objetivos orçamentários?

5- O sistema de custos é usado para a tomada de decisões?

6- Qual a regularidade da análise da taxa de ocupação hospitalar?

7- Qual a regularidade da análise do tempo médio de permanência?

8- A instituição realiza análises comparativas dos seus indicadores com os de outras instituições assemelhadas?

9- A organização realiza consultas econômicas e financeiras para a tomada de decisão?

10- Você acredita que um bom controle de custos pode auxiliar nas tomadas de decisão das organizações?
Sim. Sim. Não respondeu. Não.

Sim. Não. Não. Não.

$\begin{array}{llll}\text { Não. } & \text { Não. } & \text { Sim. } & \text { Sim. }\end{array}$

$\begin{array}{llll}\text { Sim. Não. } & \text { Sim. }\end{array}$

Sim. Sim. Não respondeu.

Diária. Diária. Diária. Diária.

Diária. Mensal. Mensal. Diária

Sim. Não. Não. Não.

$\begin{array}{llll}\text { Sim. } & \text { Sim. } & \text { Sim. }\end{array}$

$\begin{array}{llll}\text { Sim. } & \text { Sim. } & \text { Sim. }\end{array}$

Fonte: Dados da pesquisa (2018)

Com relação às tomadas de decisões dos hospitais, os gestores dos hospitais A e B dizem discutir regularmente com a liderança as informações de custos para tomada das decisões. Percebe-se uma aparente inconsistência nas respostas visto que pelas respostas, nenhum hospital possui sistema de gestão de custos, no entanto, A e B afirmaram se reunir para discutir a respeito. É possível que os respondentes tinham em mente as informações parciais de custos obtidas por meio do sistema de controle gerencial interno.

Apenas o hospital A estabelece os preços dos serviços conforme as informações dos sistemas de custos, pois mesmo não possuindo sistema de gestão de custos os hospitais possuem controles internos com informações parciais de custo. Metade dos pesquisados possuem sistema orçamentário formal e três dos pesquisados analisam as diferenças entre os resultados reais com os objetivos orçamentários. 


\section{Revista

Três dos pesquisados dizem utilizar o sistema de custos para tomar decisões, de modo que, conforme já comentado, possivelmente os mesmos estejam referindo-se às informações parciais de custos. Todos realizam a analise diária da taxa de ocupação do hospital e o tempo médio de permanência é analisado diariamente nos hospitais A e D e mensalmente nos hospitais B e C. Dos quatro, apenas o hospital A realiza análises comparativas dos seus indicadores com outras instituições assemelhadas e os hospitais A, B e C realizam consultas econômicas e financeiras para tomada de decisão. Todos os administradores dos hospitais dizem acreditar que um bom controle de custos pode auxiliar nas tomadas de decisão.

Sabe-se que toda organização seja ela de pequeno, médio ou grande porte, necessitam diariamente tomar decisões que podem definir o futuro delas. "O núcleo do processo administrativo é a decisão, a escolha, dirigida para um fim, de uma entre várias alternativas de ação a luz de algum objetivo" (HORNGREN, 2000, p.5). No entanto, para que tais decisões sejam acertadas, elas necessitam ser baseadas em informações.

Percebe-se que ainda falta aos gestores a devida consciência de que "a informação de custos, e a própria função da contabilidade de custos, assume um papel extremamente relevante no processo de gestão de um hospital, nos dias atuais (MATOS, 2002, p. 237).

Assim, embora todos os administradores acreditem que um bom controle de custos pode auxiliar nas tomadas de decisão das organizações, na prática, isso não tem sido utilizado de forma efetiva, embora algumas informações parciais de custos sejam produzidas.

É possível também que a não existência de sistema integrado de gestão de custos seja explicada pelo fato da implantação de sistema de gestão de custos em hospitais ser um processo intricado, difícil e complexo, principalmente em virtude da complexidade inerente à própria organização, visto que possui uma multiplicidade de serviços e profissionais atuando simultaneamente, e um volume expressivo de dados que precisam ser capturados e processados (OLIVEIRA, 2017).

\section{CONSIDERAÇÕES FINAIS}

A tomada de decisão em qualquer que seja a organização não é uma tarefa fácil, devem ser levados em consideração fatores que podem parecer irrelevantes, mas que no final podem fazer uma diferença significativa para a empresa. Com base nos dados obtidos por esta pesquisa, pode se concluir que os gestores dos hospitais de Tangará da Serra, ainda não tem como prioridade a utilização da gestão de custos como instrumento de produção de informação para a tomada de decisão. Embora todos afirmem que isso é importante, na prática são 


\title{
Revista

produzidas somente informações parciais de custos, pela utilização de sistemas de controle gerencial interno, os quais também são importantes, pois poderiam, mediante ampliação da abrangência, compor um sistema integrado de gestão de custos.

Quanto aos objetivos específicos desta pesquisa, pode-se verificar que todos os hospitais possuem um tempo de existência aproximado e a gestão dos mesmos é feita por administradores. Dos quatro pesquisados três são privados e um público, dois de pequeno porte e dois de médio porte.

Verificou-se que os hospitais não utilizam sistema de gestão de custos, porém todos fazem o controle parcial dos custos e controlam os gastos por meio de um sistema de controle gerencial. Com relação à tomada de decisão, os administradores responderam que utilizam as informações referentes a custos, ou seja, as informações parciais que são geradas pelos controles internos para a tomada de decisões e que tem o devido cuidado para que essas informações sejam produzidas com qualidade a fim de que sejam realmente úteis na tomada de decisão.

Sugere-se que seja realizada pesquisa em um dos hospitais a fim de apresentar uma proposta de como deveria ser estruturado um sistema de gestão de custos à luz dos princípios da contabilidade de custos.

\begin{abstract}
Cost management is a very important element in supporting the decision-making process. In view of the importance, this study aimed to verify the situation of hospitals in the city of Tangará da Serra - MT regarding the use of cost management systems. The study is characterized as descriptive and exploratory, with a quantitative approach. Four hospitals were surveyed, of which three are private for profit and one public. All managers understand the importance of the existence of a cost management system in the organization, although none of them carry out the entire process, since they only record and generate partial information about costs. All managers stated that they want to implement a cost management system in their organizations. It was evident that the hospitals surveyed are still deficient in the use of cost systems, showing the need for improvement in the instruments of information production for decision making.
\end{abstract}

Keywords: Cost management; Cost accounting; Hospital costs.

\section{REFERÊNCIAS}

ABBAS, K. Gestão de Custos em Organizações Hospitalares. 2001. 171 f. Dissertação (Programa de Pós-Graduação em Engenharia de Produção)- Universidade Federal de Santa Catarina. Florianópolis, 2001. 
BEULKE R; BERTÓ J. D. Gestão de custos e resultados da saúde: hospitais, clinicas, laboratórios e congêneres. 4. ed. rev. atualizada e aplicada. São Paulo: Saraiva. 2008. BITTENCOURT, S. A.; CAMACHO, L. A. B.; LEAL, M. C. O Sistema de Informação Hospitalar e sua aplicação na saúde coletiva. Cadernos de Saúde Pública, v. 22, p. 19-30, 2006.

BONACIM, C. A. G.; ARAÚJO, A. M. P. Gestão de custos aplicada a hospitais universitários públicos: a experiência do Hospital das Clínicas da Faculdade de Medicina de Ribeirão Preto da USP. Revista de Administração Pública, v. 44, n. 4, p. 903-931, 2010.

BRIMSON, J. A. Contabilidade por Atividade. 7. Ed. Atlas. São Paulo. 1994.

BRUNI, A. L.; FAMÁ, R. Gestão de custos e resultados na saúde: com aplicação na calculadora HP 12C e Excel. $3^{a}$. ed. São Paulo: Atlas, 2004.

CAlladO, A. A. C.; CALlADO, A. L. C.; AlBUQUERQUE, J. L.; SILVA, C.M. L.; LEITÃO, C. R. S. A influência da utilização da capacidade instalada sobre as práticas de gestão de custos em empresas agroindustriais. In: Anais do Congresso Brasileiro de Custos-ABC. 2008.

CAPPONI, N. F. Sistemas de custos em organizações hospitalares: Estudo de caso no município de Cascavel - PR, 2015, 196 p. Dissertação (Programa de Pós-Graduação em Administração) - Pontifícia Universidade Católica do Paraná. Curitiba, 2015.

CASTRO, C. A.O; SANTOS, E. M. D; HIRAIDE, R. A. B; GOMES. A. LAMEU, M. A; LIMA, I. G. A gestão estratégica de custos como diferencial competitivo para micro e pequenas empresas. Gestão em foco-UNISEPE, v. 1, p. 1-10, 2015.

CREPALDI, S. A.; CREPALDI, G. S. Contabilidade gerencial: teoria e prática. $7^{\mathrm{a}}$ edição. São Paulo: Atlas, 2014.

GERSDORFF, R. C. J. A contabilidade de custos no Brasil - Qual seria um sistema prático, simples, eficaz? Revista Brasileira de Contabilidade, 1980; 33: 34-46.

GIL, A. C. Como elaborar projetos de pesquisa. 4. ed. São Paulo: Atlas: 2002

HORNGREN, C. T. Introdução à contabilidade gerencial. 1 ed. LTC Livros Técnicos e Científicos Editora. Rio de Janeiro. 2000.

MARTINS, D. B.; PORTULHAK, H.; VOESE, S. B. Gestão de custos: um diagnóstico em hospitais universitários federais. RAHIS, vol. 12, nº 3, 2015.

MARTINS, Eliseu. Contabilidade de custos. Ed 9. Atlas, São Paulo, 2003.

MATOS, A. J. Gestão de custos hospitalares: técnicas, análise e tomada de decisão. São Paulo: Editora STS, 2002. 
MELO, R. B. Gestão de Custos nas Organizações Hospitalares: um estudo de caso. 2004, 82 p. Trabalho de Conclusão de Curso (Ciências Contábeis) - Universidade Federal de Santa Catarina, Florianópolis, 2004.

MINISTERIO DA SAUDE. Departamento Nacional de Saúde. Divisão de Organização Hospitalar. História e Evolução dos Hospitais. Rio de Janeiro, RJ, 1994.

MINISTÉRIO DA SAÚDE. Glossário do Ministério da Saúde: projeto de terminologia em saúde. Brasília, MS, 2004.

MINISTÉRIO DA SAÚDE. Programa Nacional de Gestão de Custos: manual técnico de custos - conceitos e metodologia. Brasília: Editora do Ministério da Saúde, 2006.

MINISTÉRIO DA SAÚDE. Secretaria de Atenção à Saúde. DATASUS. Cadastro Nacional de Estabelecimentos de Saúde - CNES. BraFsília; 2017. [acesso dia 11 de dezembro de 2017]. Disponível em: http://cnes.datasus.gov.br/pages/estabelecimentos/consulta.jsp

MINISTÉRIO DA SAÚDE. Secretaria de Atenção à Saúde. Reforma do Sistema de Atenção Hospitalar Brasileira. [acesso em 18 de setembro de 2008]. 2008e Disponível em: www.pbh.gov.br/smsa/biblioteca/concurso/reformasistemaatencaohospitalarbrasileira.pdf

OLIVEIRA, M. F. de. Metodologia científica: um manual para a realização de pesquisas em Administração. Universidade Federal de Goiás. Catalão-GO, 2011.

OLIVEIRA, F. O. A implantação de um sistema de gestão de custo hospital pela EBSERH: Um estudo de caso com utilização do PMBO. RAHIS, v. 14. nº 1, 2017

PADOVEZE, C. L. Contabilidade Gerencial: um enfoque em sistema de informação contábil. $7^{\mathrm{a}}$. Edição. São Paulo: Atlas, 2010.

SCHIESARI, L.M.C. Instituto Sírio-Libanês de Ensino e Pesquisa. Avaliação externa de organizações no Brasil: podemos fazer diferente? São Paulo. 2013.

SOUZA, P. C. Avaliação econômica em saúde aplicada a hospitais. Mato Grosso: Unemat, 2010.

SOUZA, P. C. de; SCATENA, J. H. G. Aplicação da gestão de custos para o aumento na eficiência dos hospitais públicos. Rev. adm. saúde, v. 12, n. 49, p. 195-207, 2010.

SOUZA, P. C.; SCATENA, J. H. G.; MEDEIROS. O sistema de informação e a gestão de custos hospitalares. Rev. Adm. Saúde, RAS _ Vol. 14, No 54 - Jan-Mar, 2012. 


\section{APÊNDICE 1}

1- As informações apuradas pelo sistema de apropriação de custos são discutidas de forma regular com as lideranças (supervisões, gerências ou direção) da instituição para tomada de decisão?
( ) $\mathrm{Sim}$
( ) Não

2- Os preços dos serviços são estabelecidos a partir dos custos hospitalares levantados para cada modalidade?

( ) $\operatorname{Sim}$

( ) Não

3- O hospital possui um sistema orçamentário formal?

( ) $\mathrm{Sim}$

( ) Não 


\section{Contabilidade}

4-São analisadas as diferenças entre os resultados reais e os objetivos orçamentários?

( ) $\mathrm{Sim}$

( ) Não

5- O sistema de custos é usado para a tomada de decisões?

( ) $\operatorname{Sim}$

( ) Não

6- Qual a regularidade da análise da taxa de ocupação hospitalar?

( ) Anual

( ) Diária

( ) Mensal

( ) Semanal

( ) Semestral

7- Qual a regularidade da análise do tempo médio de permanência?

( ) Anual

( ) Diária

( ) Mensal

( ) Semanal

( ) Semestral

8- A instituição realiza análises comparativas dos seus indicadores com os de outras instituições assemelhadas?

( ) $\operatorname{Sim}$

( ) Não

9- A organização realiza consultas econômicas e financeiras para a tomada de decisão?

( ) $\mathrm{Sim}$

( ) Não

10- Você acredita que um bom controle de custos pode auxiliar nas tomadas de decisão das organizações?

( ) $\operatorname{Sim}$

( ) Não 